\title{
Route optimization for solid waste collection: Onitsha (Nigeria) case study
}

\section{OGWUELEKA, T.C.}

\author{
Department of Civil Engineering, \\ University of Abuja, Nigeria \\ Ogwueleka@yahoo.co.uk
}

\begin{abstract}
Routing of solid waste collection vehicles in developing countries poses a challenging task. New decision procedure for solid waste collection problem was introduced in this study. The problem objective was to minimize the overall cost, which was essentially based on the distance travelled by vehicle. The study proposed heuristic method to generate feasible solution to an extended Capacitated Arc Routing Problem (CARP) on undirected network, inspired by the refuse collection problems in Nigeria. The heuristic procedure consists of route first, cluster second method. The computational experience with the heuristic in Onitsha was presented. The technique was compared with the existing schedule with respect to cost, time and distance travelled. The adoption of the proposed heuristic in Onitsha resulted in reduction of the number of existing vehicles, a $22.86 \%$ saving in refuse collection cost and $16.31 \%$ reduction in vehicle distance travelled per day. The result revealed a good performance of the proposed heuristic method, which would be useful in vehicle scheduling. @ JASEM
\end{abstract}

Solid waste collection is one of the most difficult operational problems faced by most cities in Nigeria. In most Nigerian cities, solid waste collections are done in an adhoc manner, which contributes to high solid waste collection cost. Solid waste collection vehicles are assigned to zones without any serious demand analysis, route construction being left to the drivers. Every time the vehicle is filled up, it heads to the disposal site to unload and then returns to the zones. This method contributes to high solid waste collection cost.

This research stems from the need to address the solid waste collection truck routing problem for urban areas. Emphasis is placed on minimizing the cost of solid waste collection through collection route optimisation since nearly $77-95 \%$ of the solid waste budget is spent on collection and haulage in developing cities (Ogwueleka, 2003; Agunwamba et al, 1998). Operations research techniques concentrating on the vehicle routing and scheduling of a fleet are applied to address the management concerns.

Some methods have already been advanced for improving solid waste management system. Prominent among these methods include vehicle routing and optimisation of solid waste collection routes (Chang and Wei, 2002; Mourăo and Almeida, 2000) etc. Nevertheless, the number of papers that have reported studies on scheduling and routing of solid waste collection vehicles as a method of minimizing solid waste collection cost are surprisingly low. Wang et al, (1996) proposed a model where waste collection, recycling and disposal are explicitly considered, but route design problem is solved only considering the districts as the sources of demand, without analysing collection routes inside each of the zones. Agunwamba et al, (2003) have chosen to associate the demand to a set of points representing a set of streets, instead of considering in details the arcs of the network. Solid waste is collected from different sanitation zones, transported to some transition stations, and finally to a landfill. The model developed can be used to assess the convenience of setting up a new transition station and to determine the way to transport waste. Most of these works have considered waste collection problem at a district level.

None of the above literatures took into account the road network detail in finding solution to waste collection problem. This study optimized distance travelled for an undirected capacitated arc routing problem, inspired by the refuse collection problems in Onitsha. The study's main objective was to minimise the collection cost and distance travelled by collection vehicles.

\section{Solid waste management in Onitsha}

Onitsha is located on the bank of River Niger in Anambra State of Nigeria. It lies on latitude $6^{0} 9^{1}$ North and longitude $6^{0} 49^{1}$ East of the Greenwich meridian. Onitsha with a population of 509, 500 (Census, 2006) people cover 13,249 hectares of land area. Management of solid waste in Onitsha is the sole responsibility of Anambra State Environmental Protection Agency (ANSEPA). The solid waste generation rate is $0.54 \mathrm{~kg}$ per capita per day (Agunwamba et al, 1998). Onitsha Municipality is subdivided into six zones: Okpoko, Fegge, Housing Estate, Upper Iweka, Inland and GRA.

GRA is a residential district with few businesses. The algorithm was applied to GRA, a district in Onitsha, whose urbanistic structure is similar to that of the whole town. The solid waste daily production is $66 \mathrm{~m}^{3} /$ day about $10.59 \%$ of the whole town's daily production. Presently, ANSEPA has adopted hauled container system (HSC) and stationary container system (SCS).

A very interesting result for real world problems lies in the fact that the vehicles carry excess of 5 $10 \%$ of their full capacity in the majority of trips. The total route length in GRA is $26.53 \mathrm{~km}$. The collection vehicle crew is one driver and four labourers and operate 8 hours per day with 
maximum of two collection trips per day. There is no transfer station in Onitsha. Recycling technologies are new in the town but not common. ANSEPA at the outset performs collection services 5 days in a week. Monday to Friday (8.00 am $4.00 \mathrm{pm})$. Solid waste collected is taken directly from the collection areas to the disposal site at the landfill located $10 \mathrm{~km}$ North East of Onitsha on the road to Nkwelle Ezunaka without treatment.

\section{MATERIAL AND METHOD}

Data were collected from both primary and secondary sources. Some tools of participatory appraisal techniques namely semi-structured interview schedule and focus group discussion were employed in data collection. The location of the disposal sites and collection points, serviceable streets, collection routes, vehicle speed, collection duration and frequency, number of trips per day, number and capacities of available vehicles, round trip duration, were collected.. The reliability of these data was checked by joining some of the trips and by observing same activities within the garage and outside. The traffic volume, street width, direction of traffic flow, characteristics of each street was obtained from observation and measurement. The distance was obtained by computing the Euclidean (or taxicab) distance between each pair of the nodes.

The road network of GRA, Onitsha is presented in Figure 1. The nodes were numbered for identification and each street was uniquely defined by a pair of nodes. The vehicle travelled at a speed of about $50 \mathrm{~km} / \mathrm{h}$ in the town, thus the travel time was presumed proportional to the travel distance. Inspection of overtime, incentive time, vehicle capacity utilization, distance travelled, productive time and quantity of refuse handled yielded data from which cost and efficiency analyses were made.

Residential refuse collection requires services at a large number of discrete points. These points are close together and distributed along the arcs. Algorithms for solid waste route are considered to belong to Capacitated Arc Routing Problems (CARP) (Amponsah, 2003). The Capacitated Arc Routing Problems (CARP) arises when arc has associated with it a positive demand and the vehicles to be routed have a finite capacity (Greistorter, 1994). One truck may not be able to service all the roads in a district due to its limited capacity. The CARP is to find a set of routes from a single depot that service all arcs in the network at minimal cost and subject to the constraints that the total demand on each route does not exceed the capacity of the vehicle. The cost of a trip comprises the cost of its serviced arcs and of its intermediate connecting paths. Demands are usually amount of waste to be collected along the streets (urban waste). The techniques combined computer and heuristics approaches. The study took into account the road network detail in finding solution to waste collection problem in undirected network.

The program was written in Visual. Basic.net and designed to run on a PC. The code ran on a PC with Centrino Duo $1 \mathrm{GHz}$ with 1 Gbytes RAM.

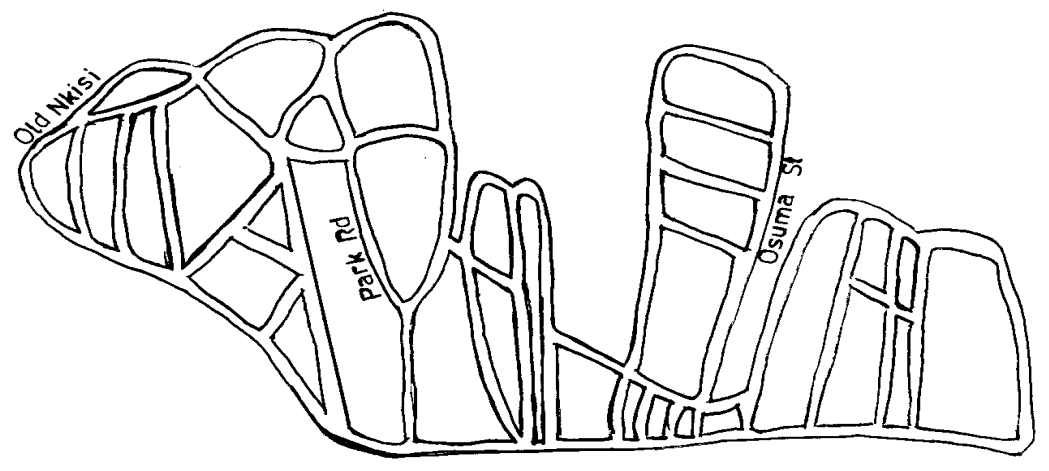

Figure 1: Map of GRA, Onitsha

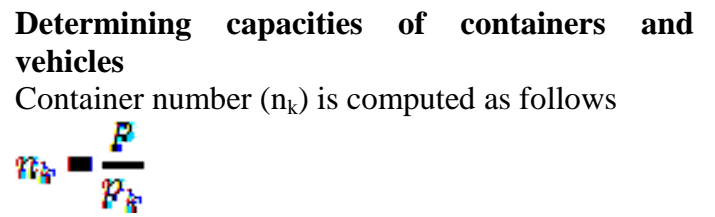

Where $\mathrm{p}$ is population living in the area and $\mathrm{P}_{\mathrm{k}}$ is population for a container. $\mathrm{P}_{\mathrm{k}}$ is written as
$r_{n}=\frac{V_{k}}{V_{R B}}$

Where $V_{k}$ is the volume of a container $\left(\mathrm{m}^{3}\right)$ and $V_{R P}$ is the volume of solid waste per person $\left(\mathrm{m}^{3}\right)$. $\mathrm{V}_{\mathrm{RP}}$ is found thus:

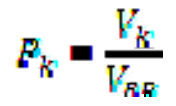


$V_{R}$ is the volume of MSW per residence $\left(\mathrm{m}^{3}\right), P_{R}$ is the number of people per residence. Solid waste container number to be collected by a vehicle $\left(\mathrm{n}_{\mathrm{k}}\right)$ is presented as follows.<smiles></smiles>

where $\mathrm{Vv}$ is the volume of a vehicle $\left(\mathrm{m}^{3}\right)$ and $\alpha$ is vehicle compaction factor.

where $\mathrm{P}_{\mathrm{R}}=4, \mathrm{~V}_{\mathrm{R}}=.0088, \mathrm{~V}_{\mathrm{k}}=0.3 \mathrm{~m}^{3}, \mathrm{P}=30,000$, $\mathrm{n}_{\mathrm{k}}=220$, and $\alpha=0.8$

\section{RESULTS AND DISCUSSION}

Comparison between existing situations and optimal results in Onitsha were done with respect to cost, time and distance travelled as shown in Table 1 and Table 2. Table 2 revealed 16.31\% reduction in travelled length and $25.24 \%$ saving in collection cost. The optimal collection was 218, 602.00 per day. In the current practice in Onitsha, ANSEPA employed four (4) vehicles, with operating cost of approximately 292, 400.00. Therefore, daily saving of proposed solution was about N73, 798.00 in collection cost and one vehicle. Cutting down the work of one vehicle would not only reduce labour and maintenance cost, but also greatly reduces total travelling distance and fuel consumption

The optimized route number and travel distances for truck types were obtained as shown in Table 3. In GRA (Onitsha) situation, vehicles of different capacities were used; open loader $\left(5 \mathrm{~m}^{3}\right)$, rear loading compactor $\left(7.5 \mathrm{~m}^{3}\right)$ and container truck $\left(15 \mathrm{~m}^{3}\right)$. The total length of routes using container truck was $81.87 \mathrm{~km}$ and that using rear loading compactor was $104.2 \mathrm{~km}$. Open loader had a total travel distance of $132.1 \mathrm{~km}$. Optimum route length required to completely service GRA is a function of truck volume and crew size. Smaller vehicles would be required to make a greater number of trips to the refuse disposal area than would large vehicles in order to service a given collection area. Route length seemed to generally increase with decrease in vehicle size. Table 4 shows the total cost comparison among vehicle classes for GRA. The total cost for using $5 \mathrm{~m}^{3}$ vehicle was $\mathrm{N}$ $302,866.00$ per day and for $7.5 \mathrm{~m}^{3}$ vehicle was

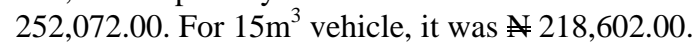
In this route optimization, the use of $15 \mathrm{~m}^{3}$ vehicle would be the most optimal

Table 1: Time and distance comparison between existing and optimal systems for GRA, Onitsha

\begin{tabular}{|c|c|c|c|c|}
\hline Route Name & Route distance, $\mathrm{km}$ & Route Time, s & Optimized Route distance, km & Route Time, s \\
\hline Route 1 & 11.43 & 2280 & 16.54 & 2780 \\
\hline Route 2 & 14.14 & 2940 & 12.44 & 2440 \\
\hline Route 3 & 13.22 & 2760 & 15.11 & 2680 \\
\hline Route 4 & 12.44 & 2820 & 11.46 & 2340 \\
\hline Route 5 & 15.73 & 3300 & 12.62 & 2480 \\
\hline Route 6 & 15.78 & 3000 & 13.70 & 2700 \\
\hline Route 7 & 15.08 & 3060 & - & - \\
\hline Total & 97.82 & 20,160 & 81.87 & 15,420 \\
\hline
\end{tabular}

Table 2: Comparison between existing and optimal systems for GRA

\begin{tabular}{llll}
\hline & & Existing & Optimal \\
\hline 1 & Total number of collection vehicles required per day & 4 & 3 \\
2 & Total vehicle distance travelled for collection per day $(\mathrm{km})$ & 97.82 & 81.87 \\
3 & Costing of hiring of collection vehicles and labour ( $)$ & 292,400 & 218,602 \\
4 & Travel time, s & 20,160 & 15,420 \\
5 & Percentage savings & & \\
& In route length & & $16.31 \%$ \\
& In collection cost & $25.24 \%$ \\
& In collection time & $23.51 \%$ \\
\hline
\end{tabular}

Table 3: Optimized route number and travel distances for truck types

\begin{tabular}{llllll} 
& Table 3: & Optimized route number and travel distances for truck types & \\
\hline $\begin{array}{l}\text { Vehicle } \\
\text { capacity, } \mathrm{m}^{3}\end{array}$ & $\begin{array}{l}\text { Total container } \\
\text { number }\end{array}$ & $\begin{array}{l}\text { Container number } \\
\text { per vehicle }\end{array}$ & $\begin{array}{l}\text { Vehicle route } \\
\text { number per day }\end{array}$ & $\begin{array}{l}\text { Vehicle travel distance } \\
\text { per day, km }\end{array}$ & \\
\cline { 5 - 7 } & & & & Collection & Hauling \\
7.5 & 220 & 14 & 16 & 36.1 & 96 \\
15 & 220 & 20 & 11 & 38.2 & 66 \\
& 220 & 40 & 6 & 45.87 & 36 \\
\hline
\end{tabular}

Table 4: Costs developed for optimized collection/ hauling as depending on truck types

\begin{tabular}{llll}
\hline Vehicle capacity, $\mathrm{m}^{3}$ & $\begin{array}{l}\text { Collection } \\
1200 \mathrm{~km}^{-1} \text { ton }^{-1}\end{array}$ & $\begin{array}{l}\text { Hauling } \\
120 \mathrm{~km}^{-1} \text { ton }^{-1}\end{array}$ & Total \\
\hline 5 & 116,242 & 186,624 & 302,866 \\
7.5 & 123,768 & 128,304 & 252,072 \\
15 & 148,618 & 69,984 & 218,602 \\
\hline
\end{tabular}


Conclusion: Adoption of the proposed heuristics decreased the number of vehicles required to complete the service from 4 to 3 . It enabled a cut back in the number of runs for trucks per day. Because of the shorter operational time and reduced runs for trucks, reductions in operational and labour cost were achieved. In the proposed algorithm, it is easier to pull a truck off the road for repair and maintenance, thus helping to extend vehicle life. The proposed heuristics provided a great deal of insight for the human router. Some portions of the routing task can be done easily by the computer while others required judgement and intuition. The new decision procedures for scheduling of solid waste collection routes would go a long way in solving the problem of indiscriminate dumping since it will reduce the collection cost, and increase the frequency of solid waste collection. Efficient routing of solid waste collection vehicles would reduce costs by reducing the labour expended in collection. The algorithm would provide optimal route, conserve energy, and reduce working hours and vehicle fuel consumption. One of the conclusions is that system analysis can be applied successfully to urban refuse management problem. The study has shown how simple heuristic methods provided decision makers with efficient solutions in the intricate problems of urban refuse administration. The success of the optimal solution provided a basis for further study on the sensitivity of the solution to the amounts of resources available.

\section{REFERENCES}

Agunwamba, JC; Ukpai, OK; Onyebuenyi, IC (1998). Solid waste management in Onitsha, Nigeria, Waste Management Research, 16 (1), 23-31.
Agunwamba, JC; Egbuniwe, N; Ogwueleka, TC (2003). Least cost management of solid waste collection. Journal of Solid Waste Technology and Management, 29, (3), 154167.

Amponsah, SK (2003). The investigation of a class of capacitated arc routing problems: the collection of garbage in developing countries, Ph.D Thesis, School of Mathematics and Statistics, University of Birmingham, UK.

Chang, NB; Wei, YL (2002). Comparative study between heuristics algorithm and optimization technique for vehicle routing and scheduling in the solid waste management system. Civil Engineering and Environmental System, 19, (1), 41-65

Greistorter, P (1994). Algorithms and implementations for the mixed capacitated Chinese Postman Problem, Working Paper 33, Department of Business, University of Graz, Austria.

Mourão, MC; Almeida, MT (2000). Lowerbounding and heuristic methods for a refuse collection vehicle routing problem. European Journal of Operational Research, 121, 420434.

Ogwueleka, TC (2003). Analysis of urban solid waste in Nsukka, Nigeria, Journal of Solid Waste Technology and Management, 29, (4), 234-245.

Wang, FS; Richardson, AJ; Roddick, FA (1996). SWIM- A computer model for solid waste integrated management. Computer, Environment and Urban Systems, 20 (4), 233246. 